\title{
A importância da motivação no trabalho da enfermagem: o papel do enfermeiro
}

\author{
Maina da Silva*
}

*Enfermeira, Graduanda do Curso de Pós-Graduação em Enfermagem do Trabalho do Centro Universitário UNA

\begin{abstract}
Resumo
Estudo bibliográfico, descritivo e exploratório que teve por objetivo compreender a importância da motivação no trabalho da enfermagem mediante o papel do enfermeiro. Foi desenvolvido através de revisão da literatura de artigos científicos e livros sobre o tema proposto. Percebeu-se que o enfermeiro, enquanto líder, deve motivar a equipe de enfermagem através do reconhecimento e valorizaçáo do trabalho executado, assim como manter um bom relacionamento com toda a equipe, o que influenciará diretamente na qualidade da assistência prestada ao paciente.
\end{abstract}

Palavras-chave: motivação, papel do profissional de enfermagem, liderança.

\section{Abstract}

\section{The importance of nursing job motivation: nurse's role}

This literature review aimed at understanding the importance of nursing job motivation through nurse role. It was developed through review of articles and books on the theme. It was noticed that the nurse as a leader should motivate nursing staff expressing recognition and appreciation of their work, as well as maintaining a good relationship with all staff, which will greatly influence the quality of care provided to patients.

Key-words: motivation, nurse role, leadership.

\section{Resumen}

\section{La importancia de la motivación laboral en enfermería: el rol de la enfermera}

Estudio bibliográfico, descriptivo y exploratorio que tuvo por objetivo comprender la importancia de la motivación laboral en enfermería mediante el rol de la enfermera. Fue desarrollado a través de una revisión bibliográfica de artículos científicos y libros sobre el tema. Se observó que la enfermera como líder debe motivar al personal de enfermería a través del reconocimiento y la valoración de los trabajos realizados, así como mantener una buena relación con todo el personal, que será de gran influencia en la calidad de la atención prestada a los pacientes.

Palabras-clave: motivación, rol de la enfermera, liderazgo. 


\section{Introdução}

O trabalho sempre teve um papel importante na vida do homem. É através dele que o ser humano transforma a natureza para produzir sua vida material e satisfazer suas necessidades. Portanto, é pelo trabalho que o homem se realiza enquanto tal [1]. Para Fryer e Payne apud Morin [2], o trabalho pode ser considerado uma atividade útil, além do prazer proporcionado por sua realização. De acordo com Baptista [1], a proporçáo que o trabalho assume na vida do homem é impossível de ser calculada.

Seguindo a mesma linha de raciocínio, Malik [3] afirma que "qualquer trabalho envolve pessoas"; Abreu e Simóes [4] corroboram a ideia do autor citado anteriormente ao afirmarem que "o trabalho é considerado como atividade essencialmente humana”. Para Morin [2], "o trabalho conserva um lugar importante na sociedade", além de proporcionar ao indivíduo um relacionamento com outras pessoas, vinculação, tarefas e objetivo na vida.

$\mathrm{Na}$ sociedade capitalista é grande a exigência de um trabalhador empenhado com o trabalho. Acrescido a isso ainda há exigências das demandas da vida pessoal, forçando os indivíduos a uma sobrecarga de atividades. A pressão exercida nas organizaçóes pode levar os trabalhadores a estados de doença, insatisfação e desmotivação [5].

Tal quadro não ocorre de forma diferente na esfera da Enfermagem. No contexto hospitalar, segundo Faria et al. [6], a enfermagem se constitui na maior força de trabalho e suas atividades são constantemente marcadas por uma divisão fragmentada de tarefas e inflexível estrutura hierárquica para o cumprimento das atividades, normas e regulamentos.

A enfermagem no contexto de força de trabalho tem um papel importante em qualquer organização de saúde seja ela pública ou privada. Todavia, conforme Barboza e Soler [7], nos serviços de saúde, principalmente em hospitais, as condições de trabalho dos profissionais de enfermagem são precárias em relação a outros serviços; como descreve Morin [2] "ao mesmo tempo em que milhares de pessoas sofrem pela falta de uma vaga, outras sofrem pelo fato de terem que trabalhar excessivamente".

Em contrapartida, quando as tarefas são realizadas com prazer, geram no indivíduo sentimentos de realização, dando um sentido ao trabalho [2]. Melara et al. [8] descrevem que é importante que as pessoas se sintam motivadas e satisfeitas para de- sempenharem bem suas funçóes. Da mesma forma, Maximiano [9] afirma que uma pessoa motivada para o trabalho possui melhor disposição para alcançar metas e realizar tarefas.

No cotidiano da enfermagem, a motivação aparece como aspecto fundamental para o alcance de maior eficiência e qualidade na assistência de enfermagem oferecida, somada à satisfação dos trabalhadores [10]. Morin [2] reforça tal perspectiva ao descrever que o trabalho exerce uma influência sobre a motivaçáo dos trabalhadores, assim como sobre sua satisfação e produtividade. Atualmente, no contexto organizacional a motivação é considerada “[...] como um dos principais fatores relacionados com a produtividade e a qualidade no trabalho" [11].

Diante disso, o enfermeiro deve desenvolver habilidades que contribuam para despertar o entusiasmo, desempenho, compromisso, motivação e capacidade de adaptação de sua equipe [12]. Destaca-se que é importante para o enfermeiro a compreensão dos diferentes fatores motivacionais para o melhor desempenho das atividades de forma individual e coletiva [13]. Galvão et al. [14] citam que muitas vezes a forma de gerenciar do enfermeiro colabora para o não atendimento das reais necessidades do cliente, além de gerar conflitos e insatisfação na equipe de enfermagem.

Assim, ao refletir sobre a motivação no trabalho da enfermagem e o papel do enfermeiro, foi constatado a respeito desta temática que poucos são os registros existentes. Diante dessas consideraçóes, emergiu o seguinte questionamento: Como as açóes do enfermeiro influenciam na motivação da equipe de enfermagem?

Assim, espera-se que este trabalho propicie a expansão da discussão crítica-reflexiva sobre o tema proposto.

\section{Material e métodos}

Trata-se de uma pesquisa bibliográfica de caráter descritivo exploratório, que objetiva compreender a importância da motivaçáo no trabalho da enfermagem mediante o papel do enfermeiro. Segundo Polit e Hungler [15] este tipo de estudo permite a compreensão de determinada realidade e, posteriormente, fornece subsídios para intervenção. Gil [16] afirma que as pesquisas exploratórias possibilitam a consideração dos mais diversos aspectos relativos ao tema estudado, assumindo, na maioria dos casos, a forma de pesquisa bibliográfica ou de estudo de caso. 
O autor afirma ainda que a pesquisa bibliográfica permite ao pesquisador a abrangência de diversos fenômenos de forma mais ampla. Todavia, torna-se necessária uma análise profunda das condiçóes em que os dados das fontes coletadas foram obtidos, com intuito de descobrir possíveis incoerências ou contradiçóes. Portanto, a pesquisa bibliográfica é produzida a partir de material já elaborado, composto principalmente por livros e artigos científicos, sendo o presente estudo desenvolvido a partir de tais fontes bibliográficas [16]. Igualmente, Severino [17] descreve que a pesquisa bibliográfica abrange a leitura, análise e interpretação de livros e periódicos, baseando-se em uma triagem de todo material recolhido, a partir da qual é possível estabelecer um plano de leitura. Para Gil [16], o estudo bibliográfico permite um amplo alcance de informaçóes e dados que podem ser encontrados dispersos em inúmeras publicações, o que contribui para melhor definir o objeto de estudo proposto.

Obedeceu-se as etapas do processo de construção de uma pesquisa bibliográfica conforme os pressupostos de Gil [16]: escolha do tema; levantamento bibliográfico preliminar; formulaçáo do problema; elaboração do plano provisório do assunto; busca das fontes; leitura exploratória do material; organizaçáo lógica do assunto e redação do texto.

Foi realizada uma pesquisa na base de dados Scientific Electronic Library Online (SCIELO), Literatura Latino-Americana e do Caribe em Ciências da Saúde (LILACS), dentro do domínio da Biblioteca Virtual em Saúde (BVS) através da conjugação dos seguintes descritores: motivação and equipe de enfermagem, motivaçáo and enfermeiro, motivação and papel do enfermeiro, motivação and liderança. Utilizou-se algumas referências citadas pelos trabalhos selecionados na base de dados devido a escassez de estudos sobre a especificidade do tema abordado; também, no acervo da biblioteca do Centro Universitário UNA em Belo Horizonte, Minas Gerais, sete livros sobre o assunto foram utilizados.

Durante a análise preliminar dos títulos disponíveis na BVS foram incluídas obras da língua portuguesa sem um recorte temporal. Foram excluídas obras por não se adequarem ao tema, não apresentarem informaçóes relevantes e pertinentes ao assunto proposto, artigos em língua estrangeira, artigos que não estão disponíveis gratuitamente em bancos de dados eletrônicos e que náo se encontram na íntegra.
Foi realizada uma leitura exploratória - segundo Gil [16] tem como objetivo verificar em que medida o material consultado interessa a pesquisa - do material selecionado mediante o exame do título e resumo, para posterior leitura na íntegra das obras. Obteve-se no final do processo um total de treze artigos.

\section{Resultados}

Ao se abordar a motivaçáo no contexto da Enfermagem é importante esclarecer as abordagens empregadas na caracterizaçáo do tema. $\mathrm{O}$ termo motivação origina-se da palavra motivu (do latim) e significa "[...] que move ou o que pode fazer mover" [10]. Por definição, motivação "[...] é a ação realizada pelas pessoas para o atendimento de necessidades não-satisfeitas" [18].

Pereira e Fávero apud Alecrim e Campos [19] conceituam motivação "[...] como uma inclinação para a ação que tem origem em um motivo, uma necessidade que, ao atuar sobre o intelecto, faz o indivíduo movimentar-se ou agir”. Para Lourenço e Trevizan [20] a motivação representa o estado em que o trabalhador tem disposição ou vontade de trabalhar de forma produtiva. Para Chiavenato [21], Marquis e Huston [18], a motivação desperta nas pessoas o desejo de trabalhar e a vontade de fazer mais, assim como de trabalhar bem e cada vez melhor.

De acordo com Maximiano [9] existem motivos ou razôes que influenciam o desempenho das pessoas, classificados em internos e externos. As necessidades, aptidóes, interesses e habilidades do indivíduo representam os motivos internos. Destarte, ao se empenhar para o alcance de um objetivo, a pessoa está de alguma forma buscando satisfazer uma necessidade. Marquis e Huston [18] corroboram esta ideia ao caracterizarem a motivação como um estímulo interno, que influencia o indivíduo na busca de algo desejado, com o objetivo de atender às suas necessidades.

Chiavenato [21] descreve que em relação à motivação, as pessoas são diferentes e, portanto, as necessidades variam de um indivíduo para o outro, resultando em diferentes tipos de comportamentos.

Em contrapartida, os estímulos ou incentivos que o ambiente oferece caracterizam os motivos externos [9]. Tanto os motivos internos quanto externos devem ser observados pelo enfermeiro, 
já que este é responsável por liderar e gerenciar toda a equipe de enfermagem. Para Pereira [22], o enfermeiro deve gerenciar o ambiente propiciando fatores de satisfação e minimizando (eliminando, se possível) os fatores de contra-satisfação. Para o autor, os fatores de satisfaçáo são representados pelas necessidades, motivos ou expectativas individuais e/ ou grupais e, a motivação ocorre quando as possibilidades nos ambientes organizacionais acontecem simultaneamente com o alcance destes fatores. Da mesma forma, quando as oportunidades náo coincidem às necessidades, são conhecidas como fatores de contra-satisfação. Assim, como cada integrante da equipe atribui um valor e sentido diferente a cada uma dessas oportunidades, se o enfermeiro considerá-las em seu processo decisório, muito provavelmente, contribuirá para despertar a motivação na equipe [23].

Cabe ressaltar que o trabalho da enfermagem muitas vezes é rodeado por atividades rotineiras, mecanicistas, baseadas em regras e normas de conduta. Além disso, a falta de recursos para resolução de problemas assim como a questão salarial também marcam a enfermagem enquanto profissão. A presença dessa realidade no contexto da Enfermagem torna a motivação da equipe uma tarefa desafiadora para o enfermeiro [21,18].

\section{Discussão}

Pelos princípios da sua própria formação, o enfermeiro tende a desenvolver habilidades de liderança, principalmente em razão das atividades que lhe são atribuídas [24]. Em concordância, Marquis e Huston [18] descrevem que todo enfermeiro é, de certa forma, líder e seu cargo exige habilidades de liderança. Para os autores, "a capacidade de reconhecer cada funcionário como um indivíduo singular, motivado de forma diferente, e de agir diante dessas diferenças constitui uma habilidade de liderança" [18]. Porém, liderar requer habilidades mais complexas do que simplesmente administrar [18].

Segundo Galvão [25], “é através da liderança que o enfermeiro tenta conciliar os objetivos organizacionais com os objetivos do grupo da enfermagem, buscando o aprimoramento da prática profissional e principalmente o alcance de uma assistência de enfermagem adequada".

O líder que motiva busca criar um ambiente de trabalho adequado para realização das tarefas cotidianas, satisfazer os interesses organizacionais e, ainda, suprir as necessidades profissionais da equipe [26]. Para Marx e Morita [27] o enfermeiro “[...] com interesse contínuo em motivar, estimular e apoiar o desenvolvimento das pessoas, de acordo com suas potencialidades, expectativas e necessidades [...]" preocupa-se com seu próprio desenvolvimento profissional.

Portanto, o comportamento de um líder representa um dos fatores determinantes de sua posição de liderança. Consequentemente, o modo de liderança desempenha grande influência sobre $o$ ambiente e sobre os resultados da equipe de trabalho. Desta forma, o cargo de líder exige do mesmo a capacidade de orientar, tanto opinióes quanto as açóes de toda equipe. Porém, cabe ressaltar que a motivaçáo da equipe não é de responsabilidade exclusiva do enfermeiro, pois cabe também a instituição proporcionar e colaborar para o processo de motivação da equipe [18].

Gindri et al. [28] corroboram tais ideias ao descreverem que motivar a equipe de trabalho e capacitá-la para obtenção de uma assistência de qualidade aos pacientes compete ao enfermeiro. Para isso, a comunicação é uma ferramenta utilizada pelo enfermeiro para o alcance de uma liderança bem sucedida, pois proporciona a este profissional desempenhar suas ações através de inter-relações com a equipe de enfermagem, resultando em melhoria na qualidade da assistência oferecida [29]. Santos e Bernardes [30] também apontam o processo comunicativo como fator indispensável para garantir que o serviço ocorra de forma eficiente e eficaz.

Galvão et al. [14] salientam que o enfermeiro deve adotar uma gerencia inovadora e utilizar a comunicação como um recurso para aproximar-se da equipe com a intenção de entender as atividades desempenhadas por cada um. Para Yoshimoto et al. [31] e para Marx e Morita [27], cabe a todo gestor manter a comunicaçáo contínua com seus subordinados, o que de certa forma, o aproxima da sua equipe, tornando-o a par das insatisfaçóes dos profissionais.

Para Marx e Morita [27] é fundamental que o enfermeiro "construa canais de comunicação acessíveis para intercâmbio de informaçóes, facilitando e mantendo o relacionamento entre a direçáo e equipe de trabalho [...]".

Uma pesquisa realizada por Simóes e Fávero [32] demonstrou que a comunicação foi o aspecto mais citado em um líder. É através da comunicação que o líder ouve novas ideias, sendo assim, 
estimulado a influenciar a equipe com suas ações, e não somente comandar ou controlar, tornando o processo bilateral [14]. Para Fernandes et al. [33], a gerência participativa é um ponto fundamental para o desenvolvimento do trabalho, pois nessa modalidade de gerenciamento a equipe procura melhorar a qualidade do trabalho, bem como suas condiçôes. Desta forma, o enfermeiro como líder enfatiza as relaçóes interpessoais e motiva a equipe [18].

Para Bezerra et al. [34], o indivíduo motivado realiza suas funçóes com qualidade, produz mais e atua de maneira mais responsável, o que consequentemente, garante a prestação de um melhor serviço para o paciente. Reconhecer o trabalho realizado por cada funcionário representa uma atitude motivadora por parte do líder [18]. O enfermeiro que motiva e valoriza sua equipe de enfermagem considera os indivíduos competentes, criativos e capazes de desempenhar suas atividades com qualidade, o que, de certa forma, auxilia no desenvolvimento das potencialidades de seus colaboradores [33]. Da mesma forma, Santos e Bernardes [30] citam que o enfermeiro deve permitir e explorar todo potencial de seus subordinados.

Ao permitir a participação da equipe na discussão das decisóes que envolvem os próprios profissionais, o enfermeiro enfatiza as responsabilidades e a percepção do sentido do trabalho em cada membro [12]. Marquis e Huston [18] concordam com a afirmaçáo anterior ao declararem que a participação leva os funcionários, de forma ativa, a tomarem decisóes que afetam seu trabalho. Para Hackman e Oldham apud Morin [2], um trabalho tem significado para o indivíduo quando ele o considera importante, útil e legítimo.

Segundo os autores Marquis e Huston [18], quando o enfermeiro comunica sua visão e a equipe tem a oportunidade de realizar o máximo com seus talentos, ele encoraja o aprendizado, a criatividade, o coleguismo, autorrespeito e profissionalismo, o que acarreta para os funcionários um espírito de motivação no ambiente de trabalho. Para os autores, o líder fortalece a equipe, orienta, dirige, motiva, enfatiza as relaçóes interpessoais, é um comunicador, energizador, pensador crítico, intermediador, influenciador, agente de mudanças, criativo.

Desta forma, o líder oferece apoio e encoraja os funcionários desmotivados. Não menos importante, também é necessário que a instituição propicie um clima que incentive a todos os empregados, estimulando desta forma, a motivação em cada um [18].
Portanto, a confiança, o trabalho em equipe, estímulo à participaçáo dos colaboradores, respeito à opinião dos trabalhadores assim como reconhecimento e valorização profissional são algumas premissas que devem ser adotadas pelo enfermeiro, enquanto líder de equipe, para criaçáo de uma atmosfera motivacional. Por fim, o enfermeiro precisa agir de maneira coerente para manutenção de um ambiente estimulante e que desperte a motivação no interior de cada um $[35,18]$.

\section{Conclusão}

A investigação do tema da motivação no trabalho da Enfermagem e o papel do enfermeiro por mais simples que possa parecer, ainda é um grande desafio para os pesquisadores em saúde.

Através da literatura consultada, percebeu-se que é necessário ao líder conhecer a fundo os aspectos relacionados à motivação. A qualidade da assistência em contextos hospitalares depende da ação e do engajamento dos profissionais envolvidos.

Ao exercer a função de liderança, o enfermeiro deverá desempenhar uma gerência capaz de proporcionar maior satisfação para os componentes da equipe de enfermagem, levando em consideraçáo os objetivos organizacionais. Nessa direção, este profissional se torna um ponto de apoio para os demais trabalhadores que, ao estarem motivados, trabalham satisfeitos e melhor.

Outro aspecto evidenciado nos estudos demonstrou que a comunicação é essencial para o desenvolvimento de uma liderança positiva exercida pelo enfermeiro em relação à equipe.

De acordo com as consideraçóes expostas, o reconhecimento e a valorização do trabalho executado, assim como o bom relacionamento entre gerência de enfermagem e a equipe assistencial foram apontados como fatores motivadores.

Os resultados evidenciaram a importância de o enfermeiro líder agir com espírito de mudança, desenvolvendo o seu papel com competência, e flexibilidade. A busca de meios para solucionar os problemas existentes na equipe contribui para melhoria das condiçóes de trabalho para os seus colaboradores.

Assim, torna-se necessário ampliar a compreensão do fenômeno que envolve a motivação dos profissionais de enfermagem através da análise de outras variáveis que podem interferir diretamente, como, por exemplo, a sobrecarga de atividades, 
condiçóes insalubres no trabalho, questóes salariais, absenteísmo e redução de integrantes da equipe, dentre outras.

Novos estudos, portanto, deverão ser realizados a fim de contribuir para maior compreensão do fenômeno, bem como trazer contribuiçóes à profissáo rumo a busca da excelência do cuidado de enfermagem à clientela.

\section{Referências}

1. Baptista RC. Doenças e outros agravos à saúde produzidos pelo trabalho. Cad Interdiscipli Saúde Tecnol Questão Social 2004;1(1):1-11.

2. Morin EM. Os sentidos do trabalho. RAE-Revista de Administração de Empresas 2001;41(3):8-19.

3. Malik AM. Gestão de recursos humanos. São Paulo: Faculdade de Saúde Pública da Universidade de São Paulo; 1998. p.137.

4. Abreu RMD, Simões ALA. Ausências por adoecimento na equipe de enfermagem de um hospital de ensino. Cienc Cuid Saúde 2009;8(4):63744.

5. Silva DMPP, Marzialle MHP. Absenteísmo de trabalhadores de enfermagem em um hospital universitário. Rev Latinoam Enferm 2000;8(5):44-51.

6. Faria AC, Barboza DB, Domingos NAM. Absenteísmo por transtornos mentais na enfermagem no período de 1995 a 2004. Arq Ciênc Saúde 2005;12(1):14-20.

7. Barboza DB, Soler ZASG. Afastamento do trabalho na enfermagem: ocorrências com trabalhadores de um hospital de ensino. Rev Latinoam Enferm 2003;11(2):177-83.

8. Melara SVG, Beccaria LM, Carta A, Contin LM. Motivação da equipe de enfermagem em uma Unidade de Terapia Intensiva. Arq Ciênc Saúde 2006;13(3):61-70.

9. Maximiano ACA. Introdução à administração. $6^{a}$ ed. São Paulo: Atlas; 2004. p.434.

10. Pereira MCA, Fávero N. A motivação no trabalho na equipe de enfermagem. Rev Latinoam Enferm 2001;9(4):7-12.

11. Bezerra FD, Andrade MFC, Andrade JS, Vieira MJ, Pimentel D. Motivação da equipe e estratégias motivacionais adotadas pelo enfermeiro. Rev Bras Enferm 2010;63(1): 33-7.

12. Pereira AA, Gonçalves B, Fernandes MBV, Pinto MAF, Antônio MS. Motivaçáo da equipe de enfermagem: competências dos enfermeiros. In: Cunha KC. Gerenciamento na enfermagem: novas práticas e competências. São Paulo: Martinari; 2008. p.49-67.

13. Melara SVG, Beccaria LM, Carta A, Contin LM. Motivaçáo da equipe de enfermagem em uma Unidade de Terapia Intensiva. Arq Ciênc Saúde 2006;13(3):61-70.

14. Galvão CM, Sawada NO, Castro AP, Corniani F. Liderança e comunicação: estratégias essenciais para o gerenciamento da assistência de enfermagem no contexto hospitalar. Rev Latinoam Enferm 2000;8(5):34-43.

15. Polit DF, Hungler BP. Fundamentos de pesquisa em enfermagem. $3^{a}$ ed. Porto Alegre: Artes Médicas; 1995.

16. Gil AC. Como elaborar projetos de pesquisa. $5^{\text {a }} \mathrm{ed}$. São Paulo: Atlas; 2010. p.184.
17. Severino AJ. Metodologia do Trabalho Científico. $22^{\mathrm{a}}$ ed. São Paulo: Cortez; 2002. p.335.

18. Marquis BL, Huston CJ. Administração e liderança em enfermagem: teoria e prática. $4^{\mathrm{a}} \mathrm{ed}$. Porto Alegre: Artmed; 2005. p.477.

19. Alecrim JS, Campos LF. Visão dos técnicos e auxiliares de enfermagem sobre o estilo de liderança do enfermeiro. Cogitare Enferm 2009;14(4):628-37.

20. Lourenço MR, Trevizan MA. Líderes da enfermagem brasileira: sua visão sobre a temática da liderança e sua percepçáo a respeito da relaçáo liderança \& enfermagem. Rev Latinoam Enferm 2001;9(3):14-9.

21. Chiavenato I. Recursos humanos. $6^{a}$.ed. São Paulo: Atlas; 2000. p.631.

22. Pereira AA, Gonçalves B, Fernandes MBV, Pinto MAF, Antônio MS. Motivaçáo da equipe de enfermagem: competências dos enfermeiros. In: Cunha KC. Gerenciamento na enfermagem: novas práticas e competências. São Paulo: Martinari; 2008. p.49-67.

23. Cunha KC. Gerenciamento na enfermagem: novas práticas e competências. São Paulo: Martinari; 2008.

24. Sousa LB, Barroso MGT. Reflexáo sobre o cuidado como essência da liderança em enfermagem. Esc Anna Nery Rev Enferm 2009;13(1):181-7.

25. Galvão CM, Sawada NO, Castro AP, Corniani F. Liderança e comunicação: estratégias essenciais para o gerenciamento da assistência de enfermagem no contexto hospitalar. Rev Latinoam Enferm 2000;8(5):34-43.

26. Amestoy SC, Cestari ME, Thofehrn MB, Milbrath VM, Porto AR. Significados atribuídos ao líder na visão de enfermeiras. Cienc Cuid Saúde 2009;8(4):579-85.

27. Marx LC, Morita LC. Manual de gerenciamento de enfermagem. 2a ed. Sáo Paulo: EPUB; 2003. p.108.

28. Gindri L, Medeiros HMF, Zamberlan C, Costenaro RGS. A percepçấo dos profissionais da equipe de enfermagem sobre o trabalho dos enfermeiros. Cogitare Enferm 2005; 10(1):34-41.

29. Galvão CM, Trevizan MA, Sawada NO. A liderança do enfermeiro no século XXI: algumas consideraçôes. Rev Esc Enf USP 1998; 32(4): 302-6.

30. Santos MC, Bernardes A. Comunicação da equipe de enfermagem e a relação com a gerência nas instituiçóes de saúde. Rev Gaúcha Enferm 2010;31(2):359-66.

31. Yoshimoto MS, Campos RD, Lima AR, Condori RCC. Comunicaçáo como competência para o processo educativo das equipes de enfermagem. In: Cunha KC. Gerenciamento na enfermagem: novas práticas e competências. São Paulo: Martinari; 2008.

32. Simôes ALA, Fávero N. O desafio da liderança para o enfermeiro. Rev Latinoam Enferm 2003;11(5):567-73.

33. Fernandes MS, Spagnol CA, Trevizan MA, Hayashida M. A conduta gerencial da enfermeira: um estudo fundamentado nas teorias gerais da administraçáo. Rev Latinoam Enferm 2003;11(2):161-7.

34. Bezerra FD, Andrade MFC, Andrade JS, Vieira MJ, Pimentel D. Motivação da equipe e estratégias motivacionais adotadas pelo enfermeiro. Rev Bras Enferm 2010;63(1):33-7.

35. Nogueira LCL. Gerenciando pela qualidade total na saúde. Belo Horizonte: Fundação Christiano Ottoni; 1996. p.94. 